\title{
E-Institute using Web Applications
}

\author{
Wasnaa Kadhim Jawad \\ Iraqi Commission for Computers and Informatics, \\ Informatics Institute for Postgraduate Studies
}

\author{
Muayad Sadik Croock, PhD \\ Computer Engineering Department, University of \\ Technology
}

\begin{abstract}
Recently, the using of electronic based institutes as a part of government has been increased sharply. This is for numerous reasons related to the flexibility and extendibility in addition to the accuracy and time saving. Human Resource Management System (HRMS) becomes prevalent in all institutions and firms due to its high efficiency that could meet work requirement. In this paper, a website based HRMS has been proposed to manage the employee's information in terms of different activities, such as promotions, salary and registration. The proposed system consists of two main parts: a website design as a Graphical User Interface (GUI) and a database. The website is designed using PHP, JavaScript, HTML and CSS environments, whereas database is built using MySQL version 5.1.30. The proposed system has been tested over different activities. The obtained results show that the proposed system has achieved a high performance and significant efficiency in terms of managing and storing the considered information.
\end{abstract}

\section{Keywords}

Human Resource Management System, Graphical User Interface, website design, database, PHP, MySQL.

\section{INTRODUCTION}

Normally, the companies and institutes either inside the government system or inside the private section aim to find out a new approach for satisfying their requirement in economy and efficient way. This is the main reason behind adopting the electronic applications in terms of website and windows. Human Resources Management System is one of the important parts in the electronic approach that uses web applications designed using (PHP, MySQL, JavaScript, HTML, and CSS). HRMS could be used in institutions and companies to organize and arrange the personnel files as well as the managing and organizing of the employees' salaries and undergone updates during the year. These types of systems face different obstacles and difficulties that can be summarized as:

- The need for corporate managers and institutions to the culture and consciousness and awareness for this system to develop and support the productivity of enterprises.

- The need to develop and train staff to use this system efficiently.

The HR systems have been considered previously in various research projects because of its substantial role and important. In [1], authors affirmed the need to standardize the research process, especially in the field of Human Resources
(HR).Researchers needed to develop a process in which development of questionnaire, administration of questionnaire and structuring of comparable measures should follow the same way. Results of such a research could not be generalized without a process which is close to uniformity. In [2],author asserted that HR represented the greatest potential competitive advantage of companies. The condition of the materialization of this prerequisite is an effective management of human resources, i.e. careful planning, organizing, leading and controlling. In [3], authors proved that High Commitment Work Systems (HCWS) are the systems that create employee commitment and includes the HR practices like employee participation, inside promotion, team rewarding, profit sharing, training and gain and job security. In[4],authors affirmed that the technological advancement can be the most challenge for the future of HRM due to one way of communication it will often create artificial distance between individuals and organizations.

The proposed system provides an automated process to store employee's information and activities, such as promotions, thanks, vacations and salaries efficiently and accurately. The PHP and MySQL environments are used essentially for designing the database and website pages in the proposed system besides other backed software. The system tackles the management and administration of the institute electronically, in which more saving in HR and efforts are guaranteed.

\section{THE SUGGESTED SYSTEM FRAMEWORK}

Figure (1) shows the outline of the suggested system framework. It displays master portions and the desired relations among them. Each system consists of its own database and tables. All of these databases and its contents are related to the main data center to supply a dynamic way of commanding the whole system.

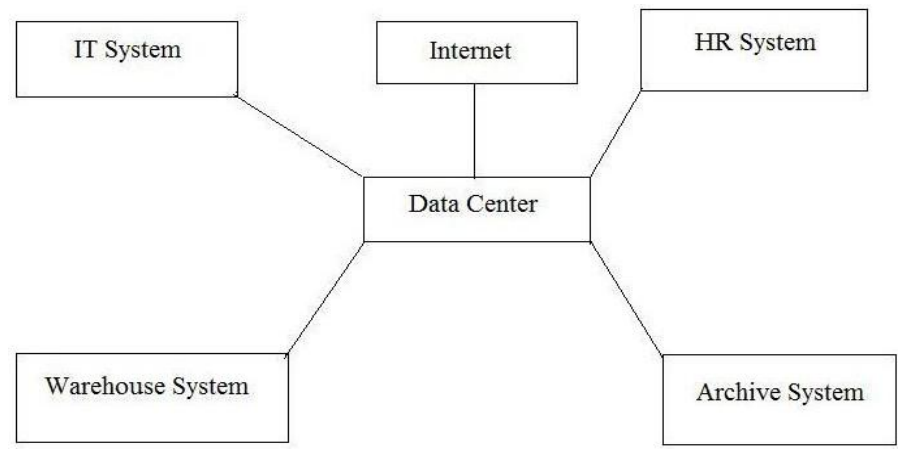

Fig.1 The Suggested System Framework 


\section{THE PROPOSED ALGORITHM}

The proposed algorithm considers the HR and the other for repository of employee's data in the database. The HR system part consists of five major processes as indicated in the Figure (2). These processes are:

- Employees: This process is used to add, update, delete and search for a specific employee as shown in Figure (3).

- Promotions: This process is used to perform the activities of adding, updating and searching of a promotion for a specific employee as shown in Figure(4).

- Thanks: This process is utilized for doing the actions related to thanks and awards including adding, updating and searching for a specific employee as shown in Figure (5).

- Vacations: This process is performing add, update and search activities of vacation for a specific employee as shown in Figure (6).

- Salary: This process is so critical and fateful, in this process allocation and presumption have been added for a specific employee. Depending on these two factors, the salary is calculated for a specific employee or for all employees as shown in Figure (7).

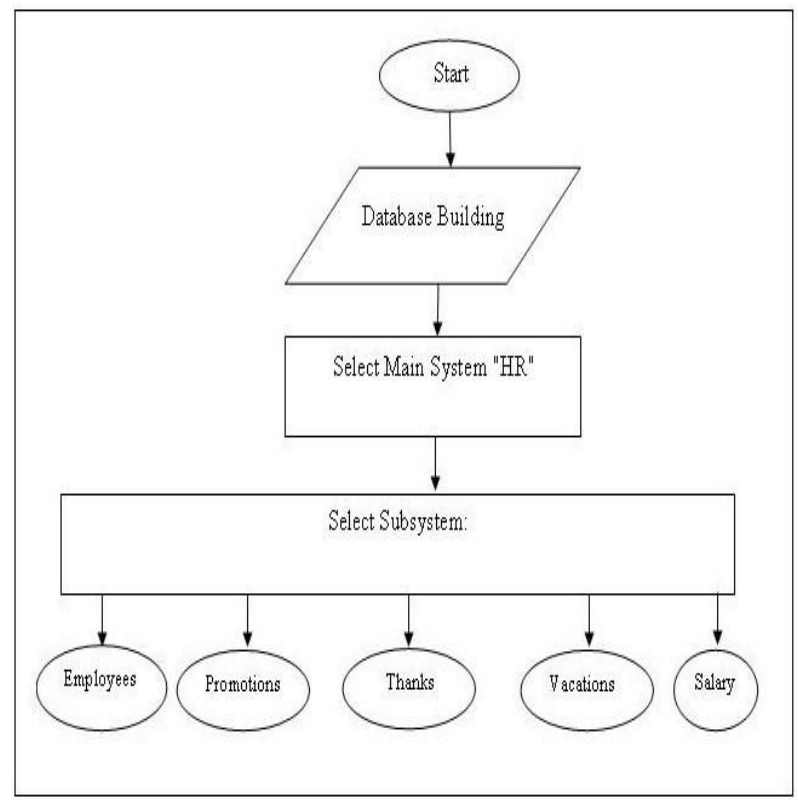

Fig.2 The HR System

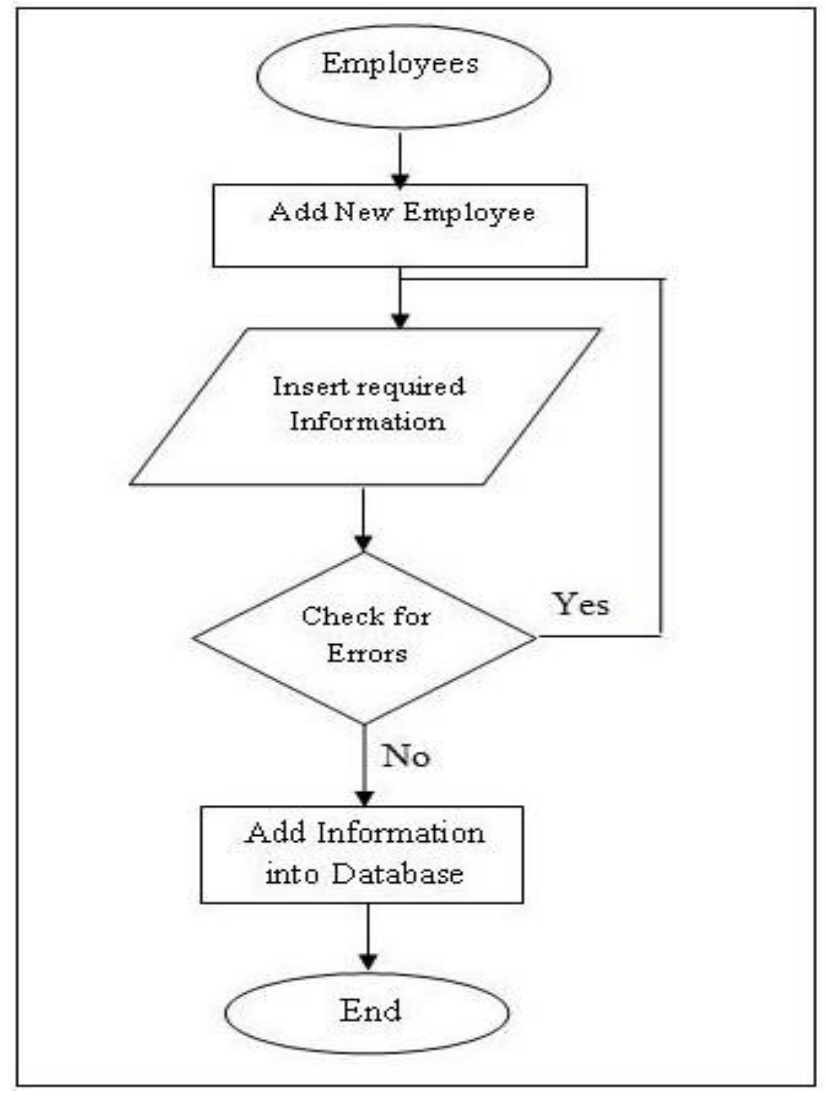

Fig.3 The Employees process

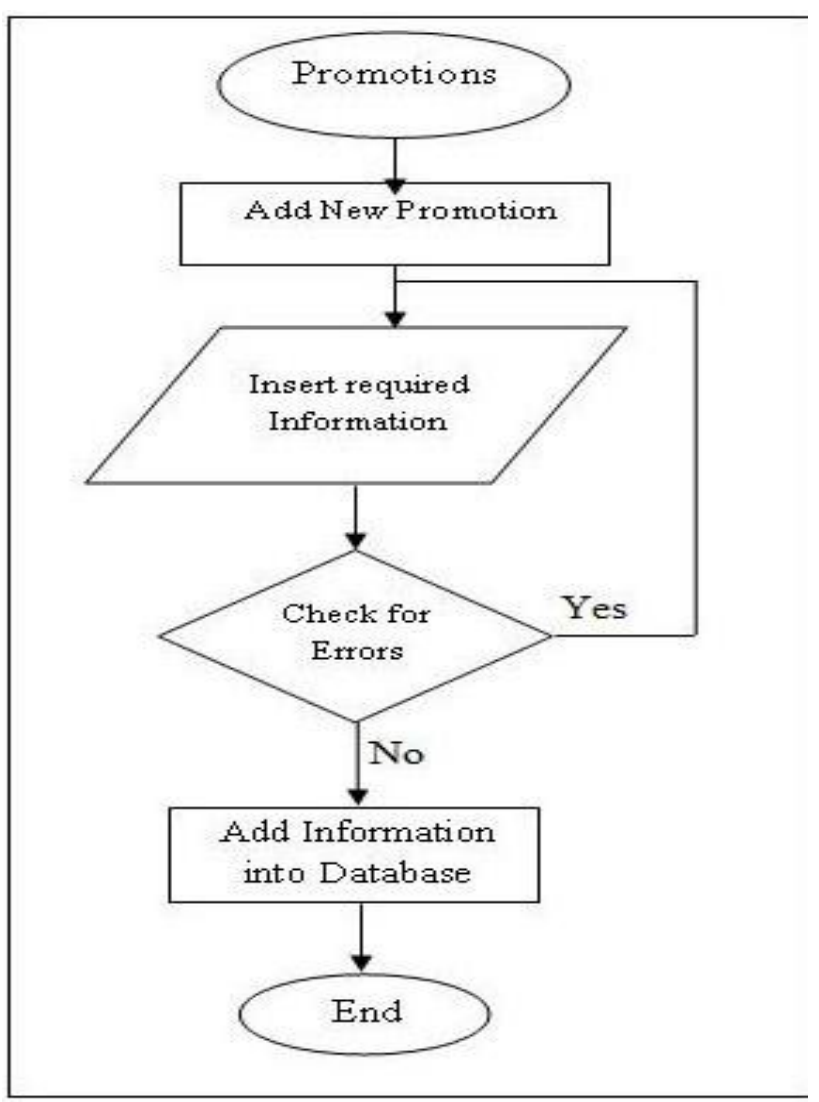

Fig.4 The Promotion process 


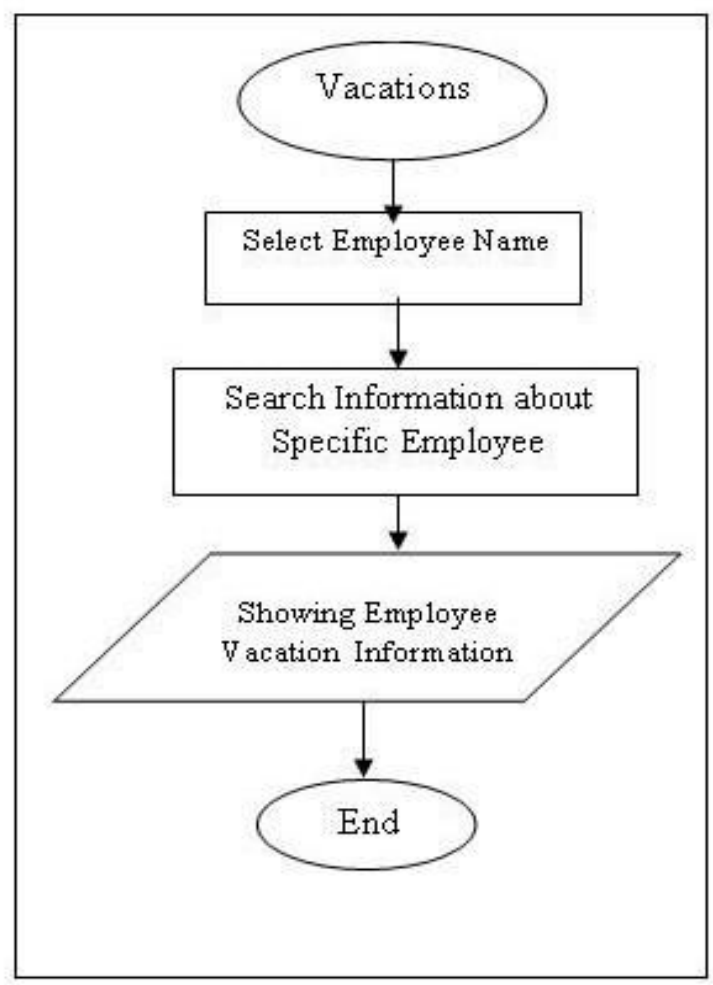

Fig.5 The Thank process

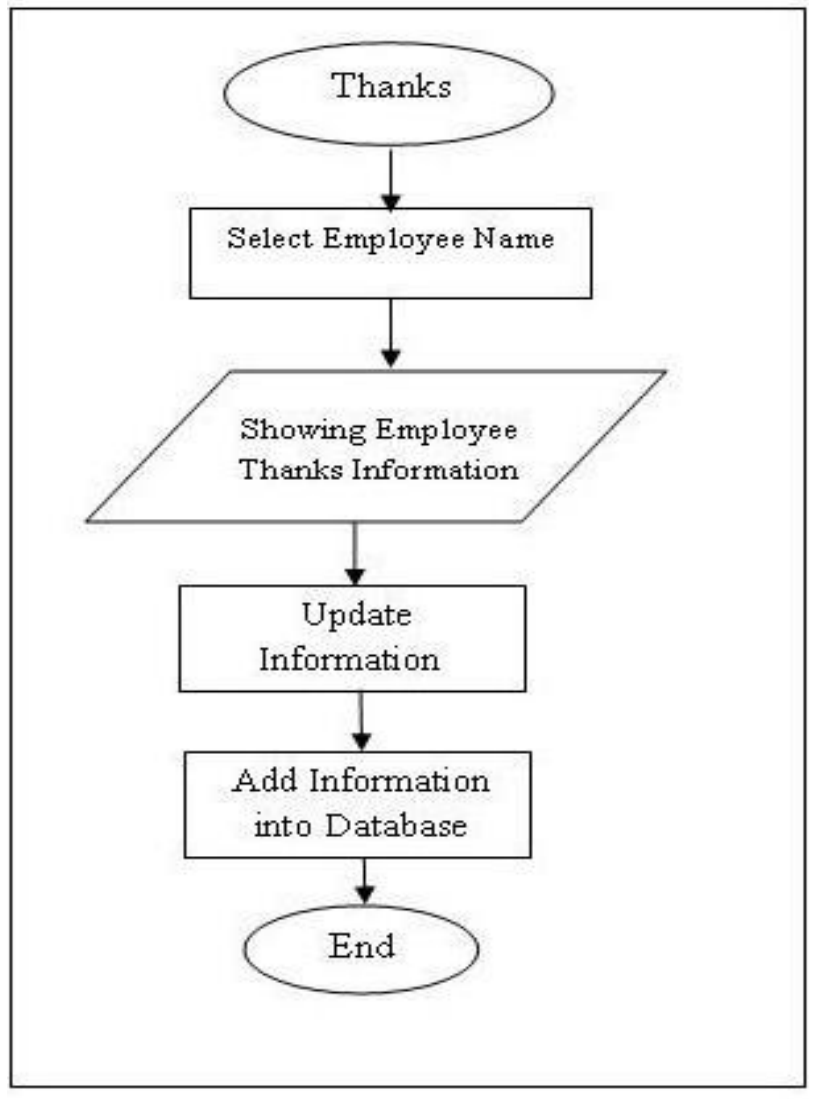

Fig.6 The Vacation process

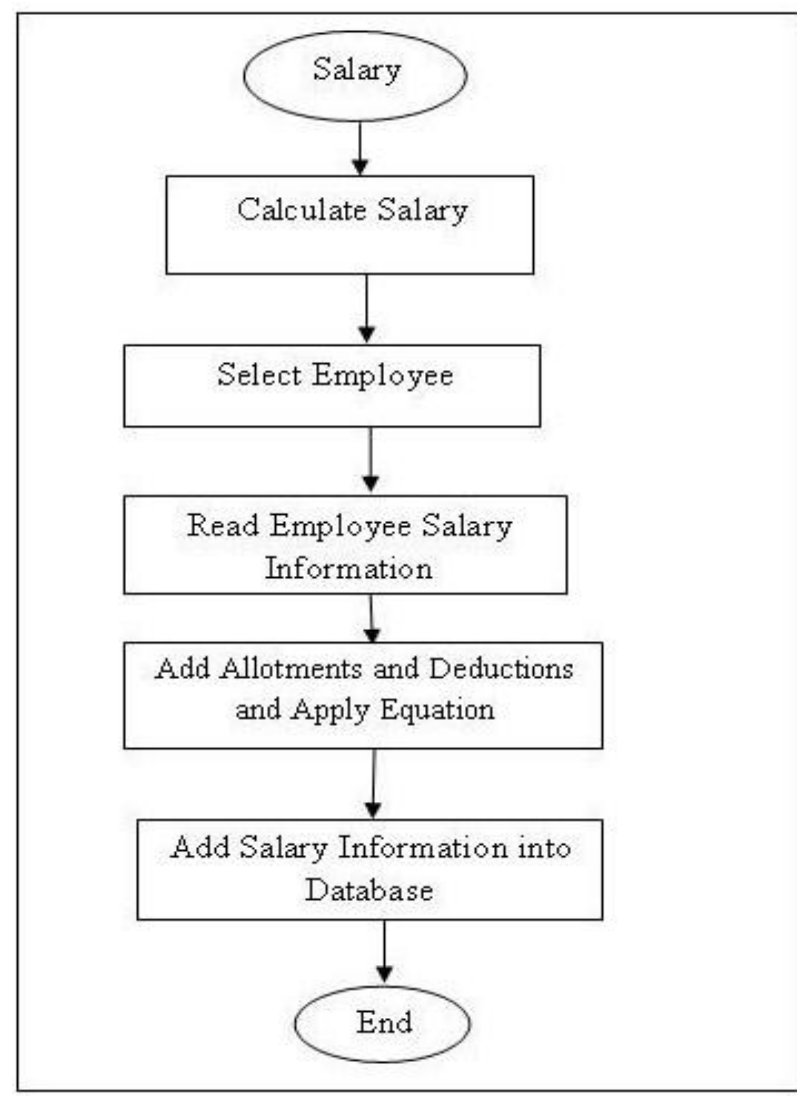

Fig.7 The Salary process

\section{DATABASE BUILDING}

For a reliable database, the MySQL environment is adopted in the building of the database. MySQL has many advantages, such as expandability and modification, powerful data preservation, supreme performance and strong transactional sustenance precisely, ease of installation, responsiveness to community [5].

In this paper, the built database is called "hr". It consists of seven relational tables linked to each other as follows:

- employees: This table consists of (17) field begins with(emp_seq: employee sequence,emp_code: employee code,emp_name: employee name,emp_birth: employee birth,emp_martstatus: employee martial status,emp_childno: employee childern number, emp_religion: employee childern number, emp_cert: employee certification, emp_degree: employee degree, emp_step: employee step, emp_basesal: employee base salary, emp_fullsal: employee full salary, emp_address: employee address, emp_commencedate: employee commence date, emp_appno: employee appointment number , emp_appdate: employee appointment date, imgname: image of administrative book ).

- promotions: This table consists of (13) field begins with (prom_seq: promotion sequence, emp_seq: employee sequence, prom_no: promotion number, prom_date: promotion date, prom type: promotion type, cur_deg: current degree, cur_step: current step, cur_add: current address, new_deg: new degree, new_add: new address,new_step: new step, stage, salary). thanks: This table consists of (6) field 
begins with (thank_seq: thank sequence, emp_seq: employee sequence, thank_bno: thank book number, thank_date: thank book date, thank_reason: thank reason,grant_dept: granting department).

- leaves: This table consists of (7) field begins with (leave_seq: vacation sequence, emp_seq: employee sequence, leave_type: vacation type, leave_bno: vacation book number, leave_bdate: vacation book date, leave_startdate: vacation start date, leave_duration: vacation duration).

- allotments: This table consists of (8)field begins with (allot_seq: allotment sequence,emp_seq: employee sequence, allot_type: allotment type, allot_amount: allotment amount, allot_ratio: allotment ratio, allot_bno: allotment book number, allot_bdate: allotment book date, allot_cont: allotment continuity ).

- deductions: This table consists of(8)field begins with (deduct_seq: deduction sequence, emp_seq: employee sequence, deduct_type: deduction type, deduct_amount: deduction amount, deduct_rate: deduction rate, deduct_bno: deduction book number, deduct_bdate: deduction book date, deduct_cont: deduction continuity).

- basesalary: This table consists of (3) field begins with (degree:employee degree, step: employee step base_salamount: base salary amount).

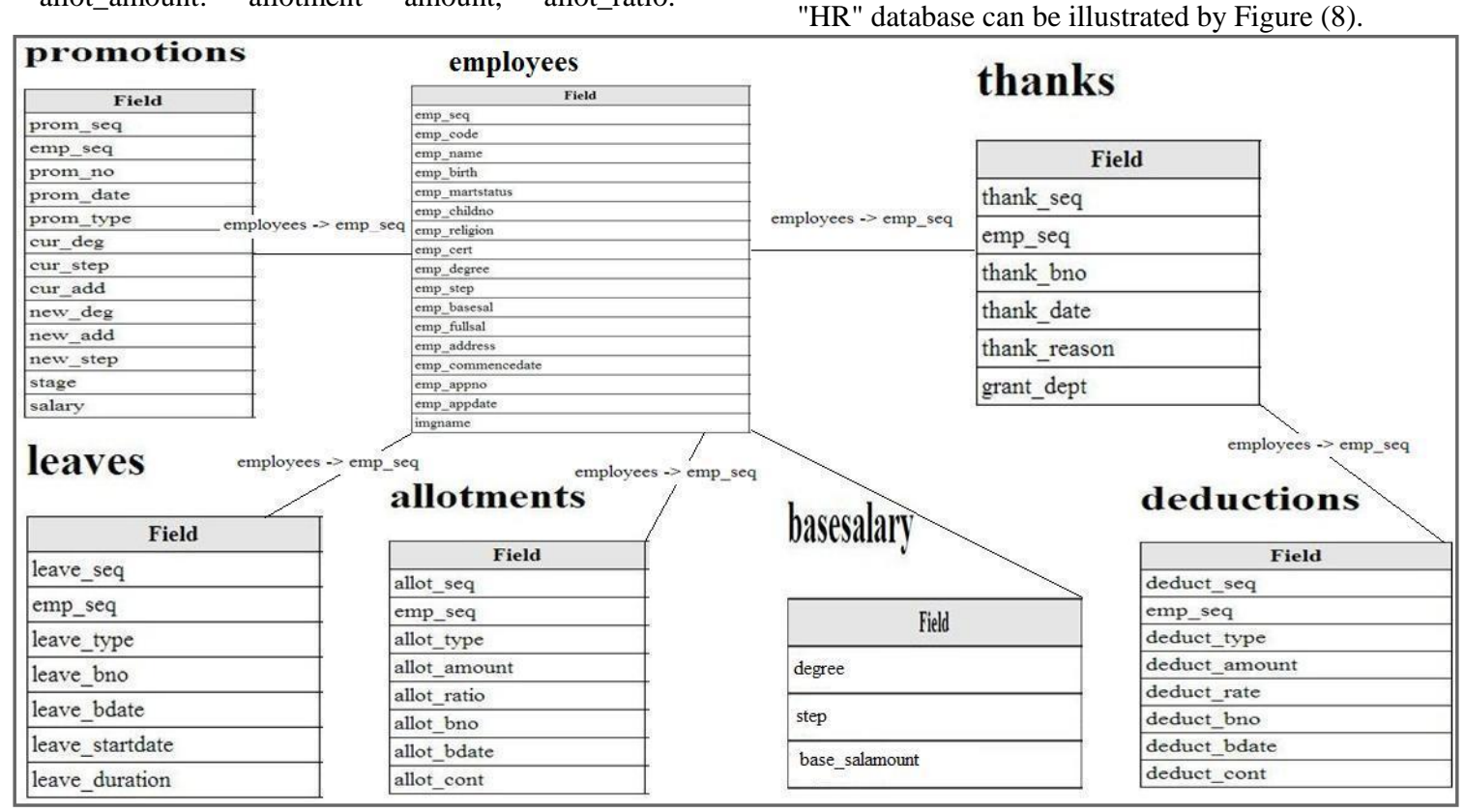

Fig.8 The HR database

\section{WEBPAGE DESIGN}

The interface of suggested system is created and run out using PHP, HTML and CSS.Figure (9) shows HR main interface and its related data. Each button in this main page has a specific function and represents a particular table in "hr" database. Figure (10) shows employees' main page and its attached data. Add new employee is performed, as showed in Figure (11),via putting all the desired information and pressing "Save Data" button; then the integrated information is stored in the required database. Update procedure is done by selecting the employee ID as showed in Figure (12).Deletion process relys on employee ID as showed in Figure(13). Searching process is done using employee'scode or name as showed in Figure(14). The resulting search show all the required information. Figure (15) shows the Thank main interface and its concering data.For example the adding of new Thank is done, as showed in Figure (16),throughout inserting the required data and clicking "Save Data".The Search and Update procedures are acheived by selecting the employee name. Figure(17) shows Vacation main interface and its linked information. The Updating procedure in Vacation main page is acheived via selecting the employee name and editing the required fields as shown in Figure(18). Figure(19) shows Salary main interface and its linked data.Throughout this page, there are different activities, such as adding of a new allotment that can be done as showed in Figure(20).

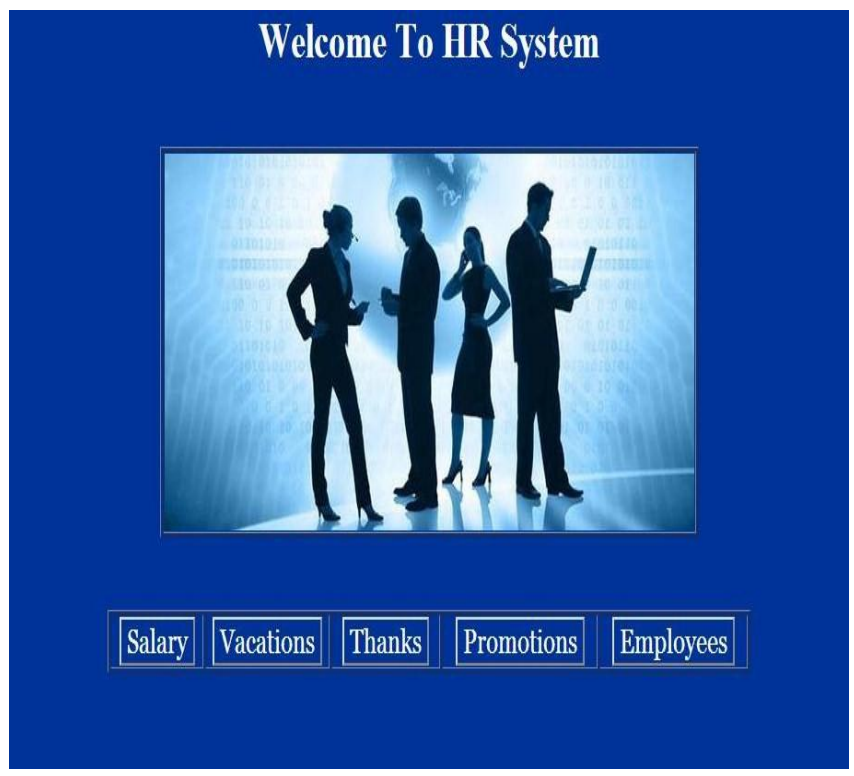

Fig.9 The HR main page 


\section{Welcome To Employees Interface}

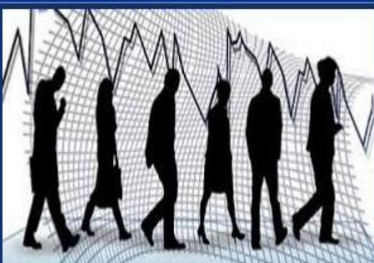

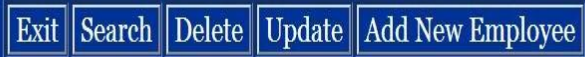

Fig.10 Employee's main page

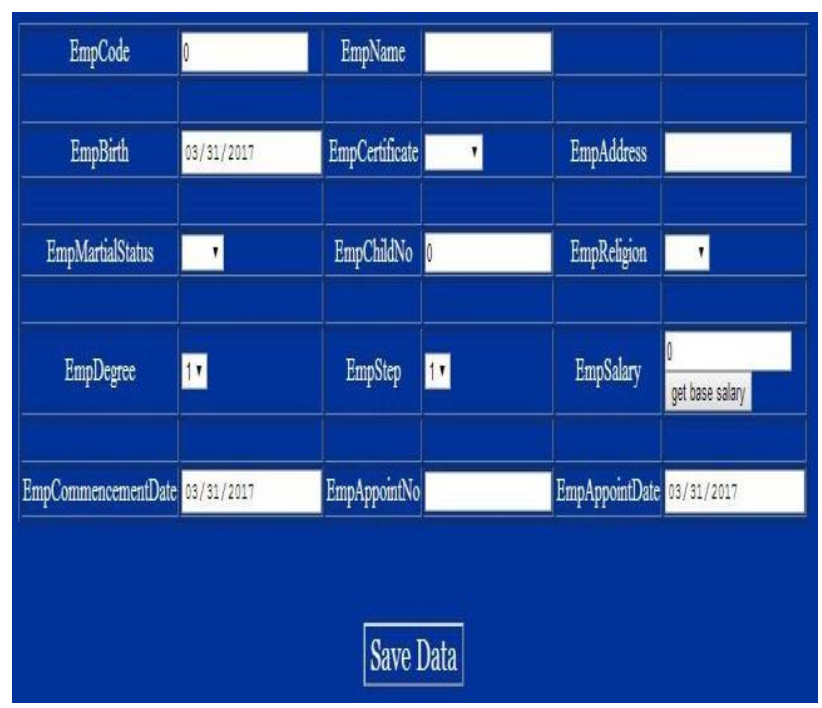

Fig.11 Add New Employee page

\begin{tabular}{|c|c|c|c|}
\hline \multicolumn{4}{|l|}{ Update data in mysql } \\
\hline EmployeeName & EmployeeMartialStatus & EmployeeCertification & Edit \\
\hline Muhannad Salman Taha Yassin & Married & Master & Edati \\
\hline
\end{tabular}

Fig.12 Update Employee page

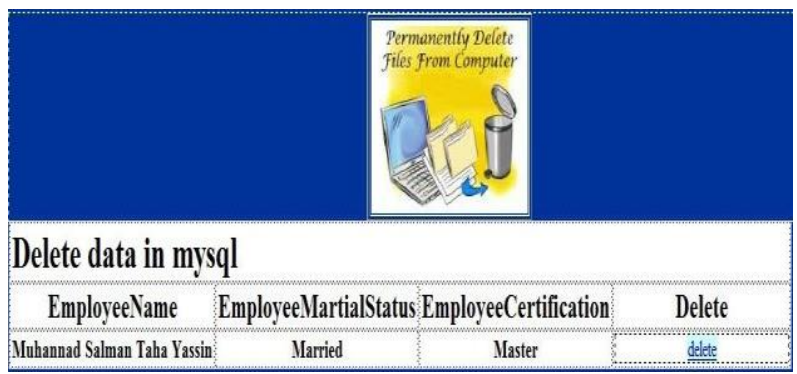

Fig.13 Delete Employee page

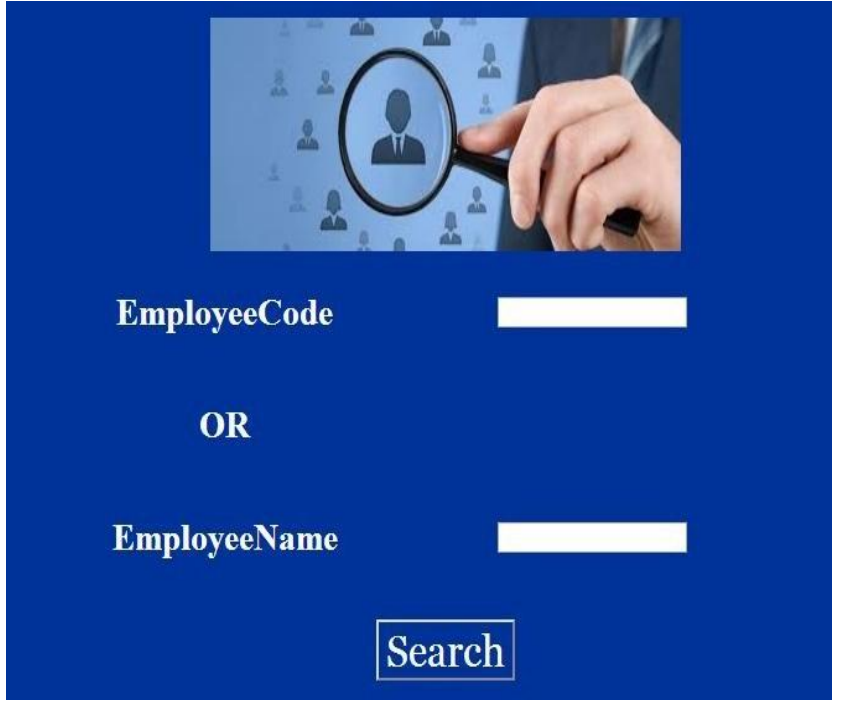

Fig.14 Search page

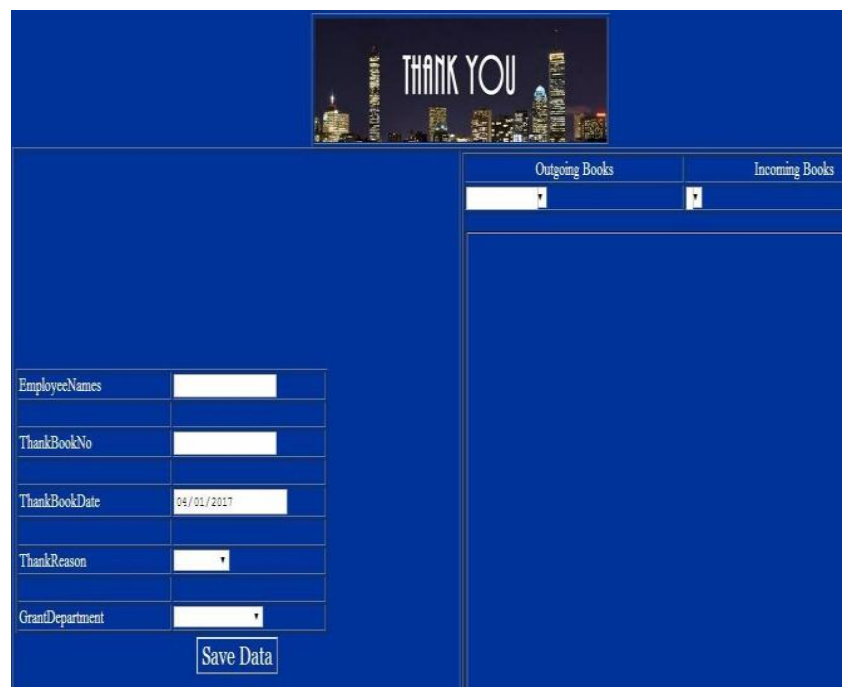

Fig.15 The Thank main page

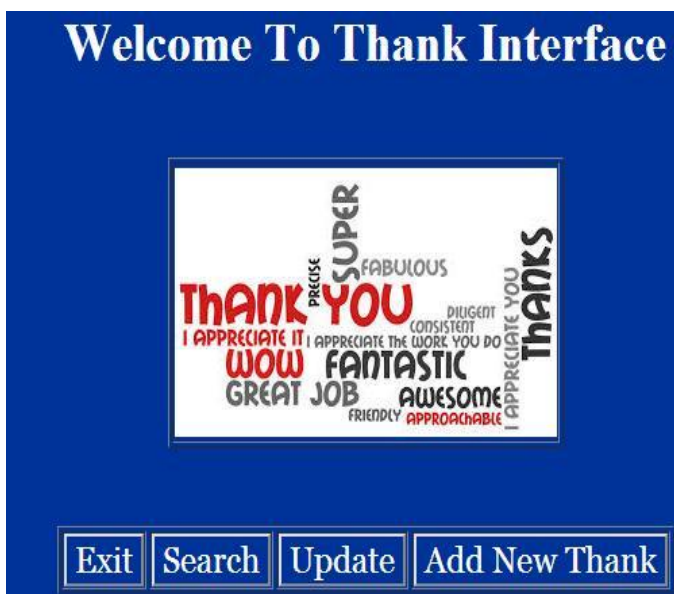

Fig.16 Add New Thank page 


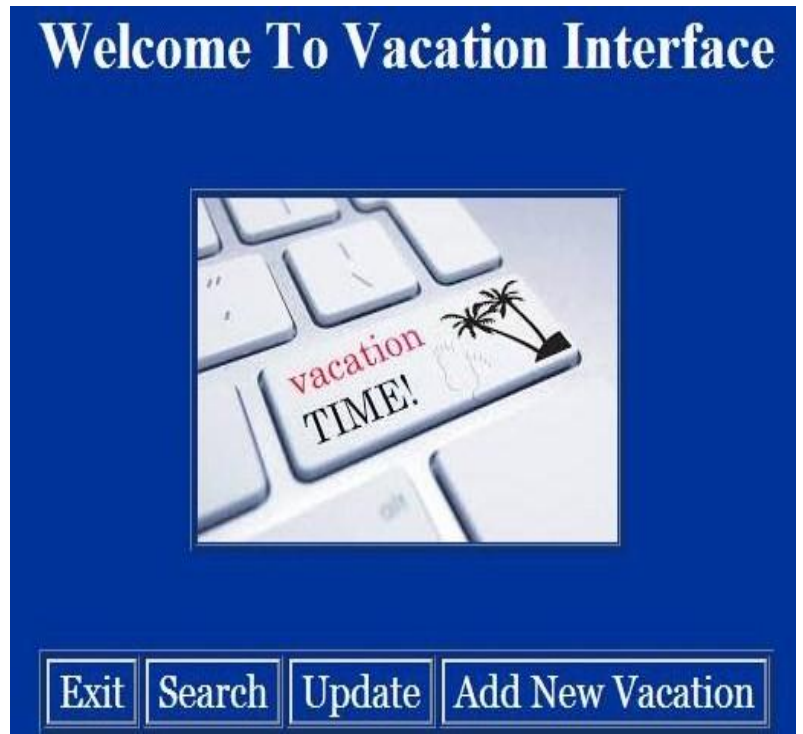

Fig.17 Vacation main page

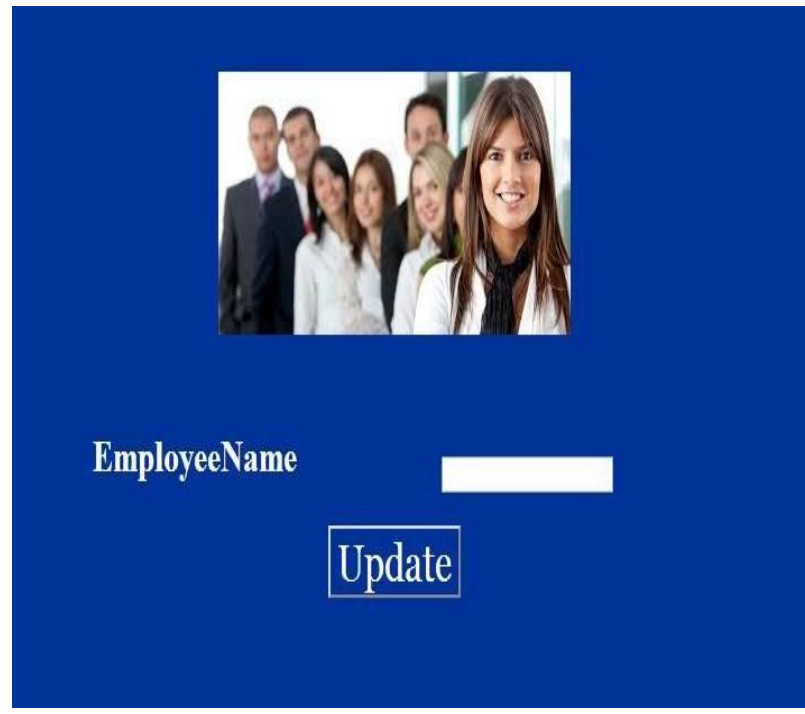

Fig.18 Update Vacation page

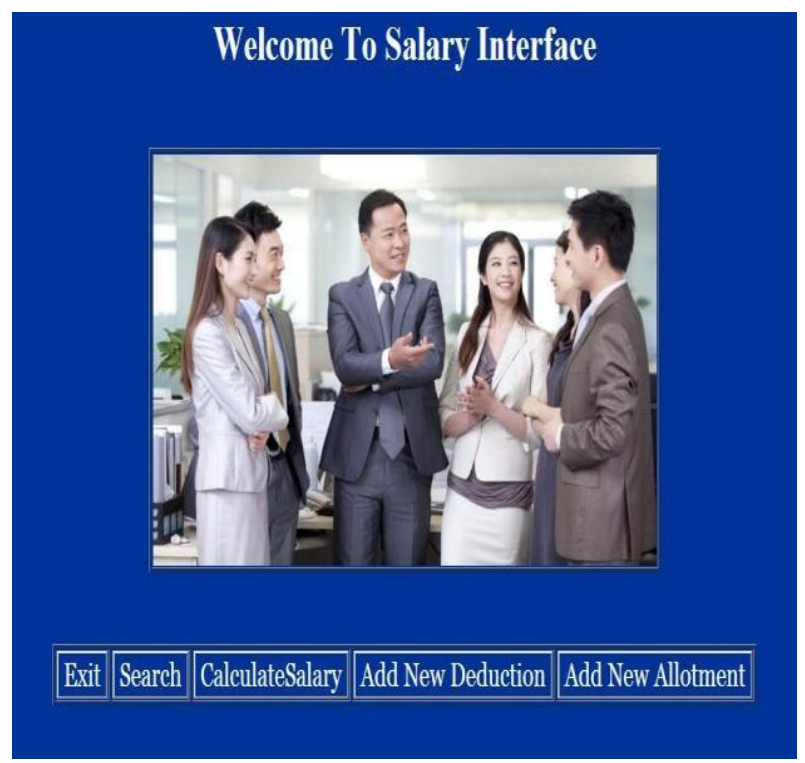

Fig.19 Salary main page

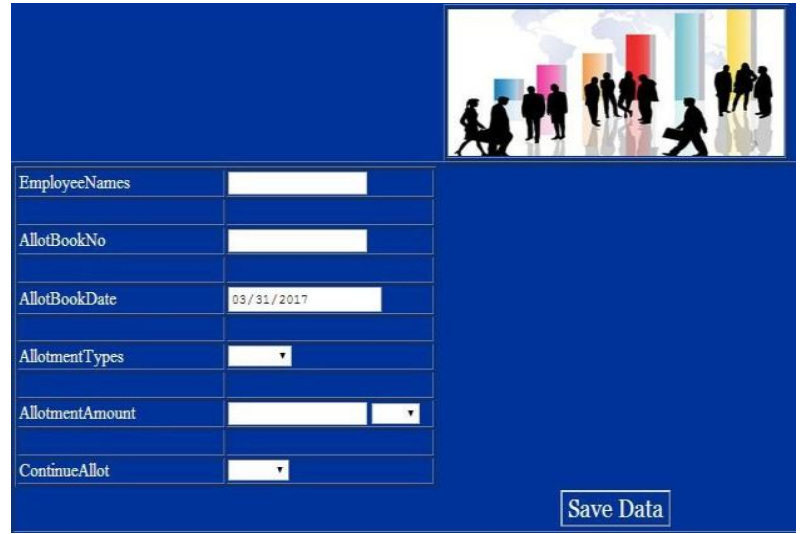

Fig.20 Add New Allotment page

\section{RESULTS}

In order to test the proposed system, different activities can be performed. As mentioned earlier, the web pages have been designed using PHP, CSS and scripting with Java. The considered database is built utilizing MySQL server.

As the proposed system includes numerous activities belong to the main HR required actions, the salary side has been adopted due to the limitation in paper number. The proposed system is tested by adding allocations and presumptions for each employee and depending on these two factors salary can be calculated for a specific employee or for all employees. Figure (21) shows salary calculation page. The procedure of calculating and searching for salary can be summarized in the next steps as:

- When the user clicks on Calculate button as showed in Figure(21),the required information about each employee and salary are calculated, as indicated in Figure(22),using the considered equation of the salary evaluation.

- When the user clicks on Search button after entering the employee's name as indicated in Figure (23), the required information about each employee and salary are searched and viewed as shown in Figure (24).

In addition the proposed system is also tested by adding new promotion for each employee deserves. The procedure of adding new promotion can be summarized as follows:

- When the user clicks on Add New Promotion button as shown in Figure(25),add new promotion is performed by inserting the required data , as indicated in Figure(26). When the user clicked on "Save Data" button these information is stored in the database.

- $\quad$ The Search procedure is acheived by selecting the specific employee name as indicated in Figure (27), the required information about each employee is searched and viewed as shown in Table (1). 


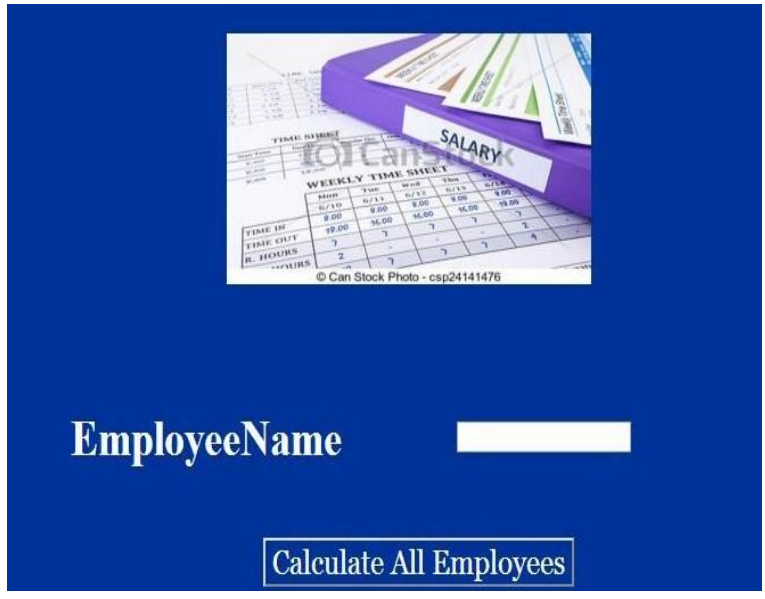

Fig.21 Calculate Salary page

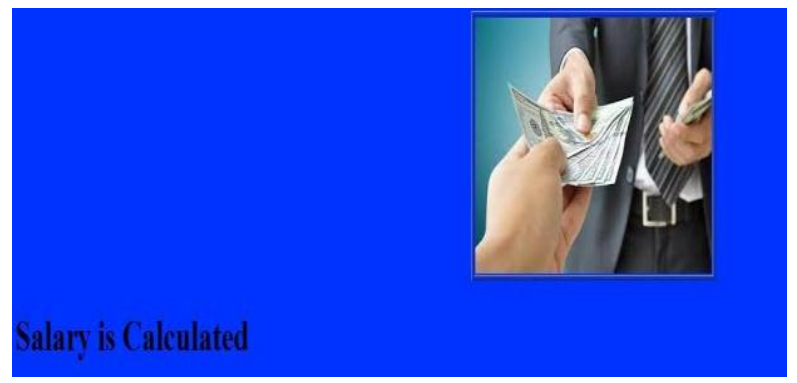

Fig.22 Salary Calculate page

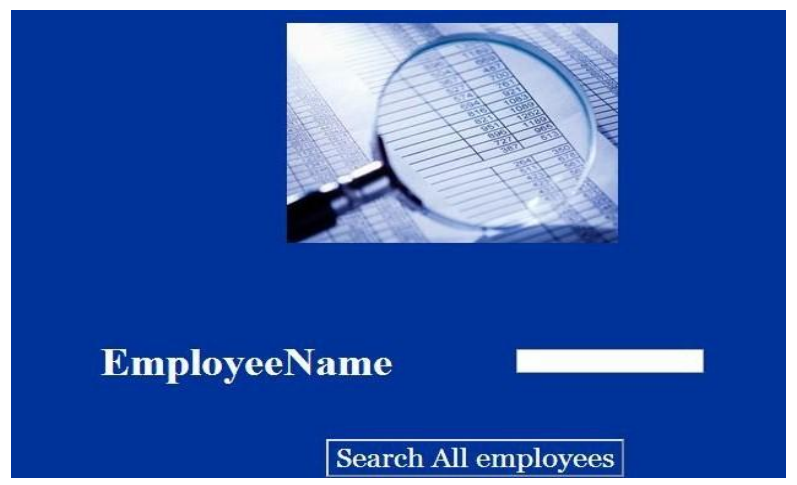

Fig.23 Salary Search page

\begin{tabular}{|c|c|c|c|c|}
\hline EmployeeCode & EmployeeDegree & EmployeeStep & EmployeeBaseSalary & EmployeeFullSalary \\
\hline 1313241 & 6 & 1 & 460000 & 652600 \\
\hline 59501 & 4 & 1 & 530000 & 746522 \\
\hline 90382 & 5 & 1 & 490000 & 808500 \\
\hline 76732 & 6 & 1 & 460000 & 665000 \\
\hline 58440 & 7 & 1 & 420000 & 567000 \\
\hline
\end{tabular}

Fig.24 Salary Search Data page

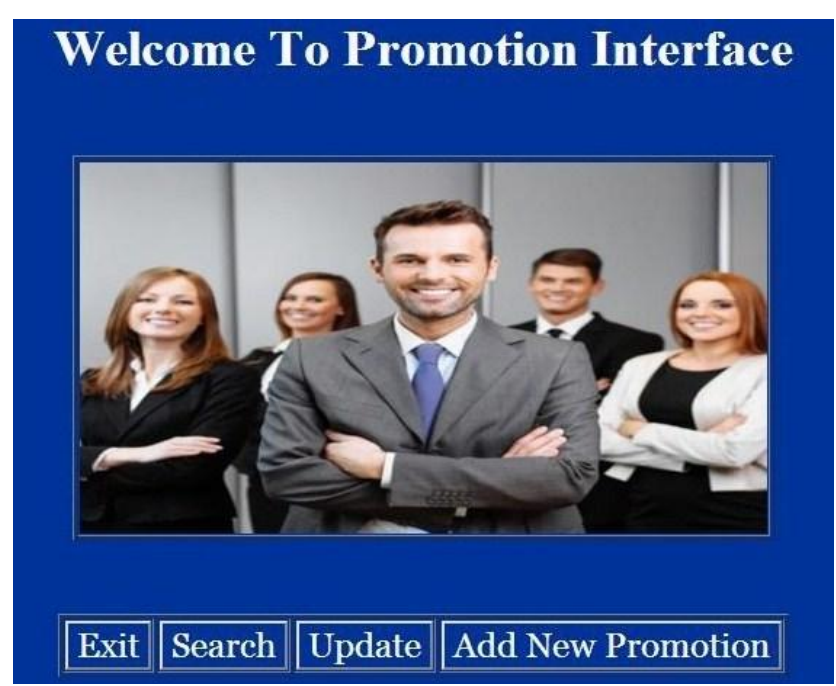

Fig.25 Promotion main page

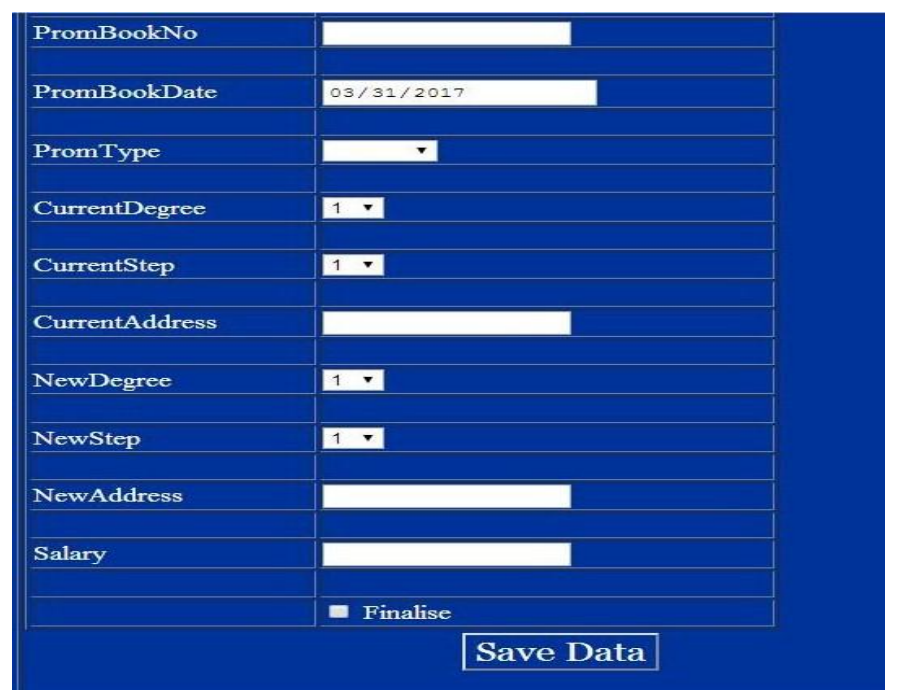

Fig.26 Add New Promotion page

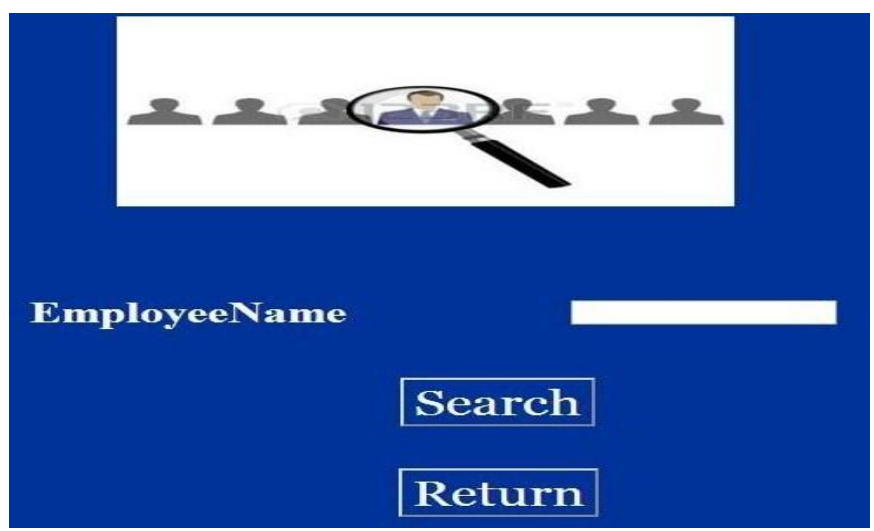

Fig.27 Promotion Search page

Table 1. Promotion Search Data page

\begin{tabular}{|c|c|c|}
\hline PromotionNo & PromotionDate & View \\
\hline 6202 & $02-11-2010$ & view file \\
\hline
\end{tabular}




\section{CONCLUSION}

The proposed system has been built over database and GUI interfaces. The database is built using MySQL environment, while the presented GUI interface WebPages has been designed using PHP, HTML, CSS and bootstrap. Electronic management depends on the use of information and communication technology to accomplish administrative transactions electronically. This can lead to reducing costs and speed of completion of transactions and simplify procedures and access to accurate and correct information and reduce the human effort significantly. The results showed that the proposed system has achieved high performance and accuracy.

\section{ACKNOWLEDGMENTS}

Thanks to the experts who have contributed towards development of the template.

\section{REFERENCES}

[1] Steinmetz, H., Schwens, C., Wehner, M., andKabst, R. (2011). Conceptual and methodological issues in comparative HRM research: The Cranet project as an example. Human Resource Management Review, 21, $16-26$.

[2] Samolejova, A., Wicher, P., Lampa, M., Lenort, R., Kutac, J., Sikorova, A., 2015. Factors of human resource planning in metallurgical company. Metalurgija 54, $243-246$.

[3] Chang, S., Takeuchi, R., Liangding, J. and Yahua, C. (2014), Do High-Commitment Work Systems Affect Creativity? A Multilevel Combinational Approach to Employee Creativity, Journal of Applied Psychology, July, 99 (4), 665-680.

[4] Stone, D. L., et al. (2015). "The influence of technology on the future of human resource management." Human Resource Management Review 25(2): 216-231.

[5] Seyed M.M. "Saied" Tahaghoghi and Hugh E. Williams." Learning MySQL", O’Reilly Media, Inc., CA 95472. USA, First Edition, November 2006. Introduction, P 4 Ch1. 